\title{
Uses and misuses of bioclimatic envelope modeling
}

\author{
Miguel B. Araújo ${ }^{1,2,3,5}$ and A. Townsend Peterson ${ }^{4}$ \\ ${ }^{1}$ Department of Biodiversity and Evolutionary Biology, National Museum of Natural Sciences, CSIC, Calle José Gutiérrez Abascal, \\ 2 28006, Madrid, Spain \\ ${ }^{2}$ Rui Nabeiro' Biodiversity Chair, CIBIO, University of Évora, Largo dos Colegiais, 7000 Évora, Portugal \\ ${ }^{3}$ Center for Macroecology, Evolution and Climate, Department of Biology, University of Copenhagen, DK-2100 Denmark \\ ${ }^{4}$ Biodiversity Institute, University of Kansas, Lawrence, Kansas 66045 USA
}

\begin{abstract}
Bioclimatic envelope models use associations between aspects of climate and species' occurrences to estimate the conditions that are suitable to maintain viable populations. Once bioclimatic envelopes are characterized, they can be applied to a variety of questions in ecology, evolution, and conservation. However, some have questioned the usefulness of these models, because they may be based on implausible assumptions or may be contradicted by empirical evidence. We review these areas of contention, and suggest that criticism has often been misplaced, resulting from confusion between what the models actually deliver and what users wish that they would express. Although improvements in data and methods will have some effect, the usefulness of these models is contingent on their appropriate use, and they will improve mainly via better awareness of their conceptual basis, strengths, and limitations.

Key words: biodiversity; biogeography; climate change; climate envelopes; conservation planning; ecological niches; invasions; niche conservation; restoration ecology; species distributions; translocation experiments; uncertainty in prediction.
\end{abstract}

\section{INTRODUCTION}

Bioclimatic envelope models - also known as "ecological niche models," "habitat suitability models," or "species distribution models" - use associations between aspects of climate and known occurrences of species across landscapes of interest to define sets of conditions under which species are likely to maintain viable populations. Although correlational in nature, these models offer an important capacity for studies in ecology and biogeography. Once envelopes are estimated, they can be applied to a variety of interesting questions, including discovery of new populations (e.g., Feria and Peterson 2002, Bourg et al. 2005), discovery of previously unknown species (e.g., Raxworthy et al. 2003), conservation planning (e.g., Williams et al. 2005, Wilson et al. 2005a, Araújo et al. 2011a), assessment of potential geographic ranges of invasive species (e.g., Broennimann et al. 2007, Peterson et al. 2008b, Villemant et al. 2011), mapping risk of disease transmission (e.g., Peterson et al.

Manuscript received 25 October 2011; revised 2 February 2012; accepted 6 February 2012. Corresponding Editor: M. Fortin.

${ }^{5}$ E-mail: maraujo@mncn.csic.es
2006, 2007), forecasting effects of climate change on species' distributions (e.g., Thuiller et al. 2005, Araújo et al. 2006, Huntley et al. 2008, Lawler et al. 2009) and on phylogenetic diversity (Thuiller et al. 2011), and identifying historical refugia for biodiversity (e.g., Waltari et al. 2007, Carnaval and Moritz 2008, Vega et al. 2010). Numerous recent reviews have been published on different aspects of this field (e.g., Guisan and Thuiller 2005, Araújo and Guisan 2006, Heikkinen et al. 2006, Latimer et al. 2006, Araújo and New 2007, Austin 2007, Jiménez-Valverde et al. 2008, Thuiller et al. 2008, Elith and Graham 2009, Elith and Leathwick 2009, NoguésBravo 2009, Huntley et al. 2010, Miller 2010, Pereira et al. 2010) and the topic has seen discussion in "perspectives" articles (Araújo and Rahbek 2006, Thuiller 2007), edited books (Scott et al. 2002), and textbooks (Franklin 2009, Peterson et al. 2011).

In short, this approach to species-level biogeography and ecology now ranks among the most widely reviewed topics in the ecological literature. Despite the great number of syntheses and the rapidly increasing numbers of primary research papers being published, much debate still surrounds the usefulness of the approach (e.g., Hampe 2004, Akçakaya et al. 2006, Botkin et al. 
TABLE 1. Some of the designations in the literature about correlative models exploring the relationship between species occurrences and environmental predictors, and their implications for interpretation of the results.

\begin{tabular}{|c|c|}
\hline Designation & Implications \\
\hline $\begin{array}{l}\text { Bioclimatic envelope models } \\
\text { (or species-climate envelope models) }\end{array}$ & $\begin{array}{l}\text { Term expressing that a multivariate space of climatic variables (the envelope) best } \\
\text { matching observed species" distributions is being estimated. The term "envelope" } \\
\text { also has been also used to refer to multivariate approaches using presence-only } \\
\text { data, but all models constructing a multivariate space of predictor variables can be } \\
\text { said to generate an envelope. The words "climate" or "bioclimatic" can be limiting } \\
\text { as species may relate to other environmental covariates; more general terms, such as } \\
\text { "abiotic" or "environmental envelope" overcome this limitation. }\end{array}$ \\
\hline $\begin{array}{l}\text { Ecological niche models } \\
\text { (or climatic niche or niche models) }\end{array}$ & $\begin{array}{l}\text { Expresses ideas analogous to those of "environmental envelope models," but instead } \\
\text { of providing descriptive terminology, an attempt is made to link the envelope to } \\
\text { elements of ecological niche theory rooted in the early work of Grinnell and } \\
\text { Hutchinson. The link between description of pattern and niche theory has raised } \\
\text { controversy, but progress is being made toward consensus. }\end{array}$ \\
\hline Habitat-suitability models & $\begin{array}{l}\text { Related to "envelope" or "niche" because it refers to the suitability of areas for } \\
\text { species rather than actual distributions. "Habitat" emphasizes the physical space } \\
\text { where species live and the resources it can use. As such, it opens the door for } \\
\text { incorporation of resource variables and biotic factors that are often absent from } \\
\text { models. The term is mostly used by researchers working at landscape scales because } \\
\text { there resolutions are those at which such connections are more easily achieved. }\end{array}$ \\
\hline Species-distributions models & $\begin{array}{l}\text { Term implying that the geographic distribution of the species is the quantity modeled. } \\
\text { Most such applications, nonetheless, characterize the multivariate environmental } \\
\text { space delimiting species' distributions, and then project this subset of environmental } \\
\text { space back onto geography. Important mechanisms, such as species dispersal, } \\
\text { establishment, and biotic interactions are not accounted for. If only suitability is } \\
\text { modeled, a species-distribution model (termed as such) will estimate something } \\
\text { more closely related to the potential distribution, and will be exposed to criticism of } \\
\text { being based on implausible assumptions and often contradicted by empirical } \\
\text { evidence. }\end{array}$ \\
\hline
\end{tabular}

2007, Dormann 2007, Sinclair et al. 2010). Criticism has typically focused on two principal contentions: (1) that models are based on implausible assumptions, and (2) that model projections are contradicted by empirical evidence.

This paper discusses these two areas of contention, and proposes that criticisms have often been misplaced, resulting from confusion between what information the models in truth deliver vs. what users think or wish that they would express. We propose that much of the confusion arises from lack of a rigorous conceptual framework for discussions, which has produced considerable semantic ambiguity (see Table 1; see also Kearney 2006, Franklin 2009, Miller 2010, Peterson et al. 2011). In effect, an incomplete grasp of fundamental concepts underpinning the models leads to significant misapplications and misinterpretations in significant portions of the literature. Although improvements in both the data and the modeling methods that are available (Thuiller et al. 2008, Brook et al. 2009, Chevin et al. 2010, Gallien et al. 2010) will have some effect, the usefulness of these models is highly contingent on their appropriate use; hence, the situation will improve most with better awareness of the conceptual bases and consequent strengths and limitations of these models.

\section{Are models based on implausible assumptions?}

Bioclimatic envelope models are based on several assumptions, some of which find strong support in ecological and evolutionary theory, while others should be better treated as "working assumptions," as they are simplifications required for building models, rather than rigorous assertions. Perhaps the most important theoretical assumption of these models is that species' distributions are determined wholly or partly by aspects of climate.

Climate, both at present and historically, governs at least the broadest outlines of distributions of species and biomes. Some might question whether the scale (e.g., Randin et al. 2009) or particular variables (e.g., Ashcroft et al. 2011, Austin and Van Niel 2011, Triviño et al. 2011) employed in a given application are appropriate, but these issues are more practical than fundamental in nature. Others have suggested that the assumption that climate determines species' distributions is neither supported nor contradicted by data (e.g., Bahn and McGill 2007, Beale et al. 2008, Chapman 2010). These criticisms are bold, as they fly in the face of the longestablished idea that climate governs species' ranges at broad extents (e.g., Von Humboldt and Bonpland 1805, Whittaker 1975, Woodward and Williams 1987, Gaston 2003, Thomas 2010). Modern evidence that climate determines species' distributions comes from at least two independent sources: (1) distributional limits of species match particular combinations of climate variables, and (2) these limits shift through time in synchrony with changes in climate. For example, Root (1988) showed that northern limits of winter ranges of birds in North America were consistently associated with minimum winter temperatures. Similarly, Walther and colleagues (2005) showed that northern range limits of the European holly Ilex aquifolium were associated the $0^{\circ} \mathrm{C}$ degree winter isotherm, and this species' range was tracking increasing temperatures through time by 
shifting distributions northwards. Corresponding upslope shifts in range boundaries along elevation gradients have also been detected both at the trailing and leading edges of distributions across elevation gradients (e.g., Wilson et al. 2005b, Lenoir et al. 2008), although patterns at the trailing edges might be often confounded by non-climatic factors (e.g., Colwell et al. 2008, Anderson et al. 2009, Hampe and Jump 2011). Evidence of contemporary range shifts matching ongoing changes in climate has been found in several taxa (e.g., Parmesan and Yohe 2003, Root et al. 2003, Hickling et al. 2006, Lenoir et al. 2008) and biomes (Gonzalez et al. 2010), and similar inferences were provided - and successfully tested - for biota in response to past climate changes (e.g., Hill et al. 1999, Araújo et al. 2005b, Green et al. 2008, Tingley et al. 2009, Dobrowski et al. 2011).

Failure to demonstrate clear species-climate associations can arise for several reasons. In the first place, the associations might have been assessed with distributional data that are incomplete or at inappropriate spatial resolution or extent. For example, Beale and colleagues (2008) evaluated climatic determination of European bird species' ranges, and purported to find negligible climatic determination; however, a parallel study using identical methods but improved distributional data for European bird species (Araújo et al. 2009) found widespread climatic determination. An analogous study applied to North American birds but conducted at an extent that included much more endemism (JiménezValverde et al. 2011a) also found strong evidence of climatic determination in the distributions of birds. Failures of attribution may also arise because the climatic variables selected are not those directly limiting the distribution of the species in question (e.g., Ashcroft et al. 2011, Austin and Van Niel 2011), as will frequently be the case with species having distributions that are structured by barriers to dispersal or by factors operating at different spatial extents or resolutions from those used in modeling. Variables used in calibrating models are generally only surrogates for the variables that affect species' distributions directly via physiological mechanisms (e.g., Austin 2007, Austin et al. 2009), so poor choice of variables for incorporation into models can affect the observed associations between species' ranges and climate. Finally, the operational formulation of null models used to examine and characterize range-climate relationships may constrain results (Fig. 1; Aspinall et al. 2009), and may frequently trade Type I errors (rejecting a correct null hypothesis of no association between species distributions and climate) for Type II errors (failing to reject an incorrect null hypothesis).

Perhaps more controversial is the assumption that species' distributions will frequently be at equilibrium with climate - that is, that species inhabit the entire spatial footprint of their habitable conditions. This assumption is known to be unrealistic (e.g., Peterson et al. 1999, Svenning and Skov 2004, Araújo and Pearson
2005, Duncan et al. 2009, Monahan 2009), since dispersal often constrains the potential of species from accessing some habitable areas, and biotic interactions, including human impacts, may further prevent establishment in some areas (Fig. 2). For example, a study quantifying range filling (i.e., the degree to which observed distributions match potential ones) among European trees (Svenning and Skov 2004), as a surrogate for species' equilibrium with climate, revealed that species in northern Europe had distributions in greater equilibrium than species in southern Europe. The authors interpreted the result in relation to the historical contingencies (e.g., presence of glacial refugia and dispersal limitation) known to affect distributions of species in the south. Another study, which overcomes the circularity of quantifying species-climate equilibrium using range filling of potential distributional areas, used physiologically derived estimates of the fundamental niche (Fig. 2), for a small number of bird species in North and South America, and compared them with estimates of the realized niche, i.e., the fundamental niche reduced by dispersal, biotic interactions, and the availability of conditions across real landscapes (Monahan 2009); results were consistent with species' distributions not being in direct physiological equilibrium with climate.

The assumption of equilibrium is a problematic working assumption necessary for applications of correlative bioclimatic envelope models, especially when models are projected to different regions or times (i.e., transferability). We emphasize the need for such assumptions to be pondered carefully and stated explicitly. Assuring that models are calibrated across the broadest spatial (e.g., Pearson et al. 2004, Broennimann and Guisan 2008, Elith et al. 2010, Kujala et al. 2011), environmental (e.g., Mohler 1983, Araújo and Guisan 2006), and/or temporal (Nogués-Bravo et al. 2008) extents that are biologically and biogeographically justifiable will help the situation by reducing the difference between the estimated realized niche and the true fundamental niche (e.g., Barve et al. 2011). However, extrapolation (i.e., projections beyond the range of environmental values used to calibrate the models) must be treated carefully (e.g., Thuiller et al. 2004b, Fitzpatrick and Hargrove 2009, Elith et al. 2010, Araújo et al. 2011a). Alternatively, physiological tolerances of species to climate (i.e., interpreted as characterizing their fundamental niches) can be estimated either from firstprinciples approaches or via experiments (e.g., Kearney and Porter 2004, Elith et al. 2010, Kearney et al. 2010, Buckley et al. 2011). However, this approach is not practical for most species, which will frequently be too poorly known to permit first-principles approaches or will prove intractable for experimentation.

In studies involving transferability of bioclimatic envelopes onto different regions or changed suites of conditions, another assumption of the models is that the dimensions of these envelopes are conserved over relevant time periods (Peterson et al. 1999). The degree 


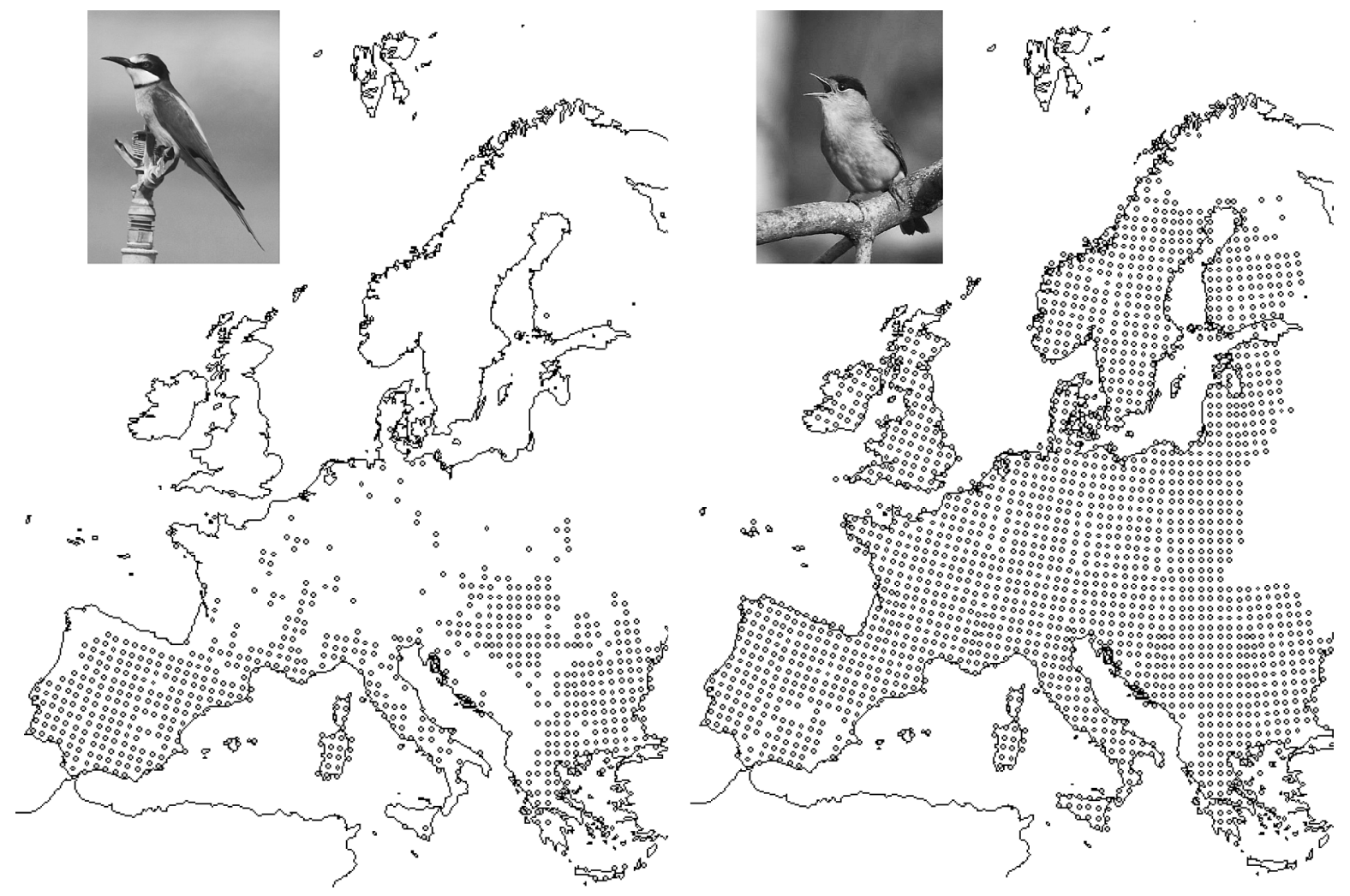

FIG. 1. Distribution of two common birds in Europe (left, European Bee-eater Merops apiaster; right, Blackcap Sylvia atricapilla). The first is a Mediterranean species that is uncommon in cooler temperate regions. The second is a widespread temperateregion species that is absent only from higher-latitude regions with subarctic climates. The scale of the grid is UTM $50 \times 50 \mathrm{~km}$. Null models comparing known geographic distributions with randomized "ranges" that preserve the spatial autocorrelation structure and leave climate data unchanged will yield random associations with climate likely to be as close as the observed ones (Beale et al. 2008). In the case of extremely widespread birds like the Blackcap, randomized distributions will resemble observed distributions closely. In the case of moderately widespread but environmentally structured species distributions, such as the Bee-eater, which has a distribution structured along a latitudinal gradient, randomized distributions are unlikely to differ significantly from them.

to which such conservatism is manifested broadly across elements of biodiversity is still a topic of debate, as rates of niche evolution and the mechanisms generating it are still poorly understood (e.g., Losos 2008, Pearman et al. 2008). The literature is often confusing with regard to the aspects of the niche that are expected to be conserved. For example, Pearman et al. (2008) noted that conservatism is achieved by stasis in the three main factors determining species' distributions (abiotic factors, biotic interactions, and dispersal), whereas nonconservatism is achieved by change in any of the three factors. However, no theoretical expectation exists for stasis in biotic interactions or dispersal: on the contrary, widespread evidence indicates that species have not always interacted with the same species as they do today (e.g., Williams et al. 2001), and they often had to move in order to track past climate changes (e.g., Clark et al. 1998). The only reasonable theoretical assumption to be made is that inherited physiological tolerances of species to environmental factors are conserved, i.e., that the fundamental niche does not change in the temporal frame involved in projections.
Studies comparing modeled bioclimatic envelopes of sister species pairs tend to find strong ecological similarity among them (Peterson et al. 1999, MartínezMeyer and Peterson 2006, Warren et al. 2008, Hof et al. 2010), and many analyses have indicated that invasive species follow the same bioclimatic frameworks in their distributional patterns manifested on different continents (Peterson 2003). Some studies have observed differences in estimated realized niches between native and nonnative ranges of invasive species, thus inviting the interpretation that niches might have evolved in the course of the invasion (e.g., Broennimann et al. 2007, Fitzpatrick et al. 2007, Medley 2010). However, tests of conservatism (that niches change more slowly than expected from Brownian motion evolution, Losos 2008) using phenomenological approaches have at least two important limitations. Firstly, as noted above, the theoretical expectation of conservatism is justified only for fundamental niches. Estimates of realized niches typically represent subsets of the fundamental niche (Fig. 2), thus observed shifts in estimated realized niches might simply indicate that different portions of the 

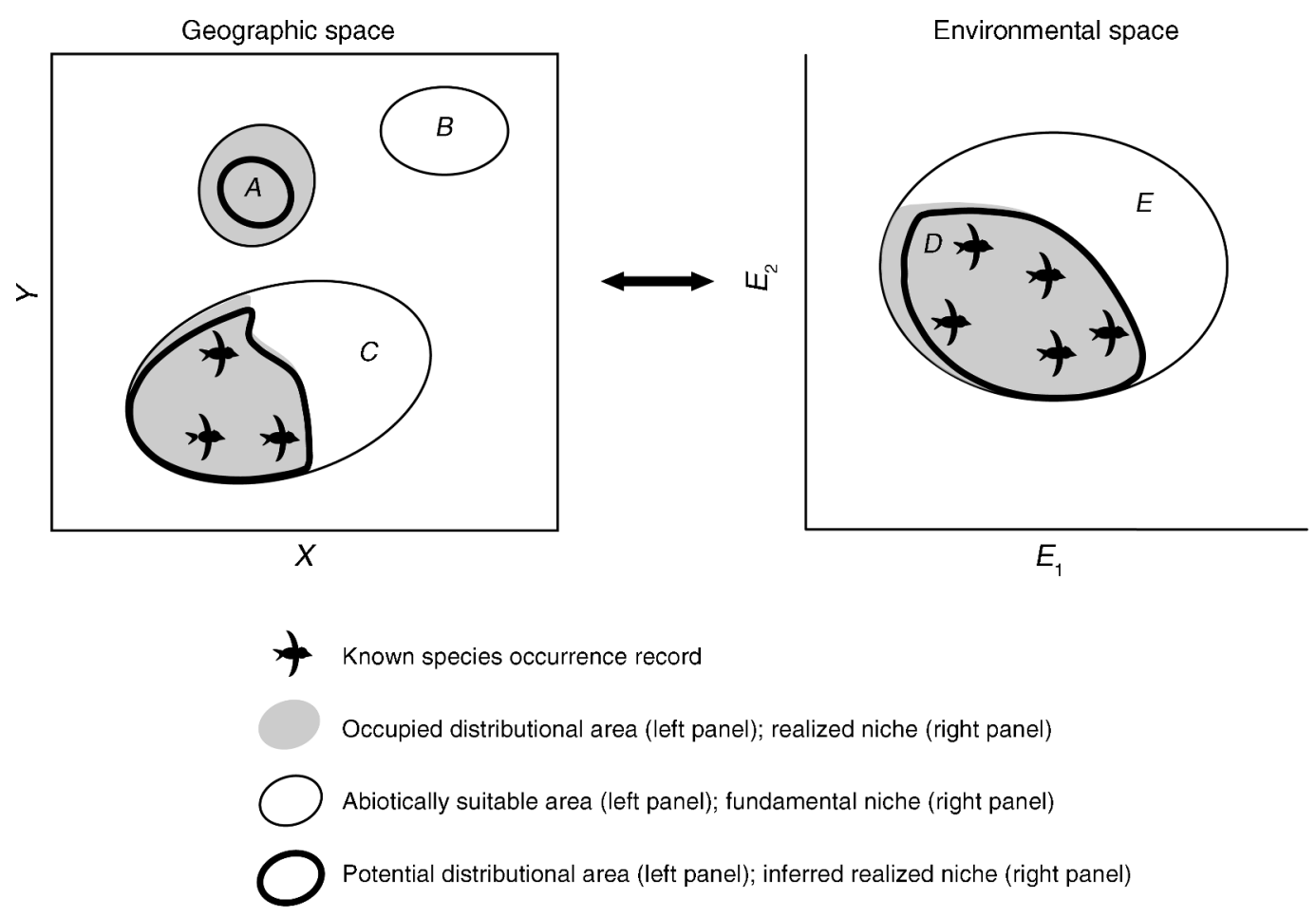

FIG. 2. Illustration of the relationship between the different distributional areas of a species in geographic and environmental space, and its modeled distribution and niche. In geographic space, area $A$ is occupied, but the species has not been detected; area $B$ is suitable, but the species was unable to colonize it due to dispersal limitation (e.g., existence of a barrier); area $C$ is suitable, but species occupancy was prevented due to biotic interactions (e.g., competition). (Note that species may occur outside of suitable areas in what are termed "sink" populations). In environmental space the union of areas $D$ and $E$ constitutes the fundamental niche. Shaded areas around $D$ comprise the realized niche; non-shaded areas around $E$ identify those parts of the fundamental niche that are unoccupied. With standard strategies that evaluate predictive accuracy of models, predictions of occurrence for $A-C$ are treated as errors of commission when, in fact, the model is correctly predicting the existence of suitable climatic conditions for the species. Over-fitted models will often underestimate the occupied distributional area, whereas under-fitted models will overestimate it. The figure is redrawn and modified from Fig. 2 of Pearson (2007) with permission.

fundamental niche are being occupied by the species in different regions and times (e.g., Nogués-Bravo et al. 2008, Soberón and Peterson 2011). Secondly, tests of niche conservatism based on empirical associations between observed species' occurrences and climate are typically unidirectional. That is, similarity between estimates of realized niches compared across regions or times is consistent with the hypothesis that fundamental niches remained unchanged (Peterson et al. 1999, Martínez-Meyer and Peterson 2006, Rodríguez-Sánchez and Arroyo 2008), but failure to demonstrate such similarity does not prove the contrary, because many alternative explanations exist.

Given the theory (Wiens and Donoghue 2004, Wiens and Graham 2005) and the weight of existing empirical evidence, it is reasonable to expect that some significant degree of conservatism of the fundamental niches exists that provides predictability across taxa, environmental dimensions, and time frames considered in most studies using bioclimatic envelope models (e.g., Kozak and Wiens 2006, Peterson 2011).

Bioclimatic envelope models have also been criticized for making overly simplified assumptions about dispers- al and biotic interactions (Dormann 2007, Zurell et al. 2009). Specifically, they have been criticized for assuming that species would either not disperse or disperse without limitations, while ignoring the role of biotic interactions in shaping current and future distributions. However, these assumptions are not integral to the models per se since the models aim only to estimate suitable conditions across landscapes, and not population processes such as dispersal (Brook et al. 2009). In reality, dispersal and biotic interactions do constrain current distributions of species; as such, they are expected to contribute to shaping the realized niche of a species and its geographic representation, particularly in constraining them from achieving full equilibrium with current climate (Fig. 2).

A very different matter is whether dispersal (e.g., Collingham and Huntley 2000, Engler and Guisan 2009) and biotic interactions (e.g., Araújo and Luoto 2007, Baselga and Araújo 2009, Meier et al. 2010) should be marshalled to constrain predictions of models when they are applied to forecasting distributional potential in different regions or under other sets of conditions (e.g., Dunn et al. 2009, Araújo et al. 2011b). These consider- 
TABLE 2. The "confusion matrix" used to calculate measures of predictive accuracy for bioclimatic envelope models, with predictions classified into four categories: true presences, true absences, errors of commission, and errors of omission.

\begin{tabular}{|c|c|c|}
\hline \multirow[b]{2}{*}{ Observation } & \multicolumn{2}{|c|}{ Prediction } \\
\hline & Species presence & Species absence \\
\hline Species present & $\begin{array}{l}\text { True presence } \\
\text { Site suitable, species present }\end{array}$ & $\begin{array}{l}\text { Error of omission } \\
\text { Site unsuitable, species present } \\
\text { (model misspecified) } \\
\text { Site unsuitable, species present } \\
\text { (model right, data wrong) } \dagger\end{array}$ \\
\hline Species absent & $\begin{array}{l}\text { Error of commission } \\
\text { Site unsuitable, species absent } \\
\text { (model misspecified) } \\
\text { Site suitable, species unrecorded } \\
\text { (model right, data wrong) } \\
\text { Site suitable, species absent } \\
\text { (model right, but incomplete) } \ddagger\end{array}$ & $\begin{array}{l}\text { True absence } \\
\quad \text { Site unsuitable, species absent }\end{array}$ \\
\hline
\end{tabular}

Note: While errors of omission are often a symptom of misspecification of the model, errors of commission reflect a variety of factors, some of which are not an indication that the prediction is erroneous.

$\dagger$ When envelope models are established with clear links with ecological niche theory, only viable breeding populations should be modeled. If sink populations are not included in the models, then errors of omission should indicate model failure.

$\$$ The inference of suitability from the models is correct but factors unaccounted for in the model (e.g., dispersal and biotic interactions) can prevent the species from occupying the full extent of suitable areas for the species.

ations are of particular concern when the focus of model predictions is on the actual distributions, rather than on distributional potential more generally (Fig. 2). Dealing with dispersal and biotic interactions in such contexts is far from trivial and requires approaches that go beyond the analytical framework offered by bioclimatic envelope models (e.g., Keith et al. 2008, Anderson et al. 2009, Fordham et al. 2012).

\section{Are models contradicted by empirical evidence?}

Mismatches between observations and predictions have been recorded chiefly in studies investigating climate change impacts on species' distributions (Araújo et al. 2005a), although congruence between observed and predicted range shifts have also been demonstrated (Hill et al. 1999, Araújo et al. 2005b, Green et al. 2008, Kharouba et al. 2009, Dobrowski et al. 2011). Debate also exists as to whether models successfully estimate climatic suitability for species (Pearce and Ferrier 2001, Wright et al. 2006), although again positive examples exist (Araújo et al. 2002, VanDerWal et al. 2009b, Kearney et al. 2010). Further research is needed to understand the dimensions and implications of these mismatches and exceptions, but a more general question is whether mismatches between projections and observations represent genuine model failure (Table 2).

Projections of bioclimatic envelope models are usually evaluated via measures that weight errors of commission (i.e., predicted occurrence where the species does not occur) and omission (i.e., predicted absence where the species actually occurs) equally (e.g., Liu et al. 2005). Although more stringent tests have assessed whether observed trends in species' range shifts match predictions (Araújo et al. 2005b), here too commission and omission errors have been weighted equally. However, bioclimatic envelope models estimate potential distributions (i.e., the geographic projection of the estimated realized niches of species), rather than the occupied distributional area of the species (Araújo and Guisan 2006, Soberón 2007, 2010, Hirzel and Lay 2008, Soberón and Nakamura 2009). Species' ranges are rarely sampled exhaustively, and many species are absent from some areas presenting suitable environments, thus creating considerable "apparent" commission error. As such, one has no objective way to discern true error of commission (as defined above) from correct prediction of habitable area in an unsampled or truly unoccupied area (Peterson et al. 2008a), unless carefully designed translocation experiments are undertaken. Balancing omission and commission errors in ways that are not necessarily even can provide useful internal guidance for modeling efforts (Anderson et al. 2003), and can help with setting more effective and informative thresholds in predictions of species' presence and absence on maps (Peterson et al. 2008a).

In the case of bioclimatic envelope models, the onus is thus on the ability to outline the spatial distribution of suitable environments for the species of interest under diverse circumstances (Jiménez-Valverde et al. 2011b). The only study known to us that has provided a direct test of the ability of correlative bioclimatic envelope models to characterize the spatial distribution of suitable areas (Kearney et al. 2010) showed that their results were comparable with the estimates of the fundamental niche estimated via eco-physiological models.

In effect, when models evaluate the suitability of particular environments for species to maintain populations with reference to a set of predictor variables, and then are evaluated against observed occurrence records, errors of commission may indicate more than failure of the model to characterize suitability correctly (Table 2). Rather, much of commission error is actually prediction of potential presence in unsampled areas, or factors not included in the modeling effort may explain the absence 
of the species from otherwise suitable areas. In other words, mismatches between prediction and observation do not necessarily mean that the model is wrong, but simply that the model might be incomplete (Oreskes et al. 1994). This problem is general with modeling of environmental systems: only closed systems, such as mathematical treatments, can prove a model wrong by recording mismatch between prediction and observation. In open systems, such as the situation at hand, demonstration of agreement between observation and prediction is inherently and invariably partial (Oreskes et al. 1994, Araújo et al. 2005a).

\section{Discussion}

\section{Are bioclimatic envelope models useful?}

The two areas of contention reviewed in this article coincide broadly with the benchmarks proposed by Hodges (1991), in a thoughtful essay on properties and uses of "bad" models for military combat. The author argues that bad models are those that are either contradicted by some data or are grossly implausible in some aspect they purport to represent; other bad models are conjectural, i.e., they are neither supported nor contradicted by data, either because data do not exist or because they are equivocal (Hodges 1991). Here, we have shown that criticisms leveled at bioclimatic envelope models are often debatable. Although fitting bioclimatic envelope models requires some weak working assumptions, in most cases the grounds for criticism are misperceptions of the portions of the niche being estimated by models, and the consequences of these differences for model calibration, evaluation, and interpretation (for an extended discussion see Peterson et al. [2011]).

To illustrate these principles, let us consider a few applications of bioclimatic envelopes that can be considered useful or not. For example, if models are used to estimate the potential distribution of an endangered species, perhaps in the context of a translocation experiment to save the species from climate warming, modeled climatic envelopes may be used to characterize areas to which the species can be reintroduced. In a counterexample, however, if the challenge is to estimate extinction risk for species over coming decades in the face of changing climates (e.g., Thomas et al. 2004), the models only estimate the empirical relationships between species' present-day distribution and climate variables, and use the inferred relationships to identify potential distributional areas of the species under future climate scenarios. Here, the quantity of interest (extinction risk), however, is not represented among the input data and thus is not the target of the modeling exercise (Ladle et al. 2004); the usefulness of this model is thus open to debate, because only partial evidence exists that shifting climate suitabilities within the modeled time frame could speak to the reasons for which the species might go extinct (e.g., Thuiller et al. 2004a, Akçakaya et al. 2006, Botkin et al. 2007, Hampe and Jump 2011). This pair of examples illustrates how inappropriate application of bioclimatic envelopes can cause problems with interpretation and conclusions, emphasizing the importance of proper framing of their use in appropriate biological questions.

\section{Cautionary notes for use of bioclimatic envelope models}

Several authors have provided guidelines for correct implementation of bioclimatic envelope models. Some are specific to the modeling technique used (e.g., Breiman 2001, Elith et al. 2008, 2010, Phillips and Dudík 2008), while others are more general (e.g., Franklin 2009, Miller 2010, Peterson et al. 2011). General guidelines include strategies for the selection of appropriate predictor variables in the models (e.g., Elith et al. 2005, Heidy Kikillus et al. 2010, Ashcroft et al. 2011), the decision as to whether background or pseudo-absence data are warranted and how to select them (e.g., Phillips et al. 2009, VanDerWal et al. 2009a, Wisz and Guisan 2009), choice of methods to convert probabilities of occurrence or suitability scores into projections of species presence and absence on maps (e.g., Liu et al. 2005, Freeman and Moisen 2008, Nenzén and Araújo 2011), decisions regarding methodology for model evaluation (e.g., Hirzel et al. 2006, Raes and ter Steege 2007, Peterson et al. 2008a, Phillips and Elith 2010), and use of ensemble and consensus forecasting methodologies (e.g., Araújo et al. 2005b, Diniz-Filho et al. 2009, Marmion et al. 2009, Garcia et al. 2012). It is clear that decisions regarding the technical implementation of the models will affect their quality, a topic that has received extensive treatment and reviews elsewhere (Araújo and Guisan 2006, Heikkinen et al. 2006, Latimer et al. 2006, Austin 2007, Thuiller et al. 2008, Elith and Graham 2009). However, methodological decisions should also be contingent on the user's intent. That is, no universally correct way exists to implement bioclimatic envelope models, and modelers should be careful to adopt protocols consistent with the ecological and biogeographical situation, meeting predefined goals of the study, and nonetheless conforming to the constraints imposed by the available data.

An important set of questions must be clarified at the outset of any study using these approaches. First and most basically, one should ponder whether the model is used to investigate and understand environmental correlates of species' distributions (explanation), or whether it is used to make inferences about the details of their geographic distributions (prediction) (e.g., Elith and Leathwick 2009). If prediction is the focus, then it is important to know if transferral is involved and, more importantly, what component of the species geographic or environmental range is being estimated (Peterson et al. 2011). The most common predictions of bioclimatic models in ecology, evolution, and conservation are explored in Fig. 3, with reference to the diagram provided in Fig. 2. Below, we discuss some of these applications in more detail. Of considerable importance is the observation that many applications focus on 
Discovery of new populations or species

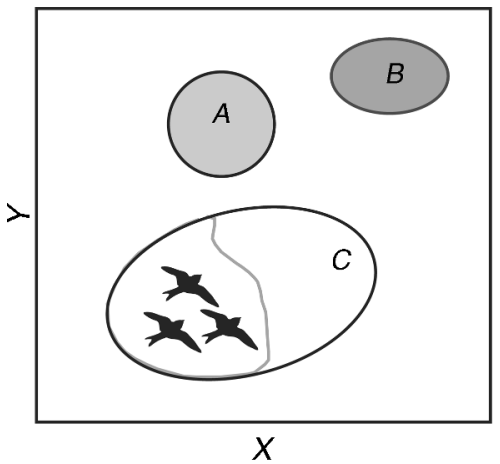

Risk of species invasions and disease

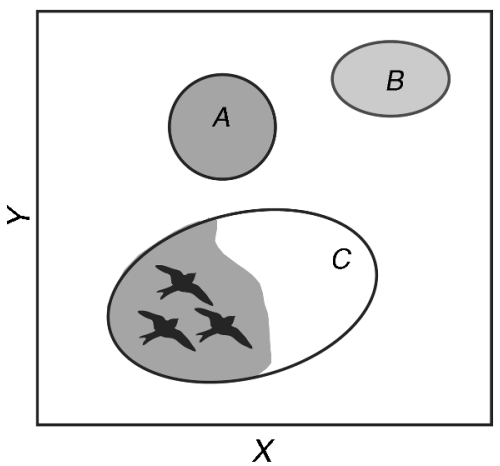

Known species occurrence record

Abiotically suitable area; fundamental niche

Alternative model predictions
Reserve selection and design

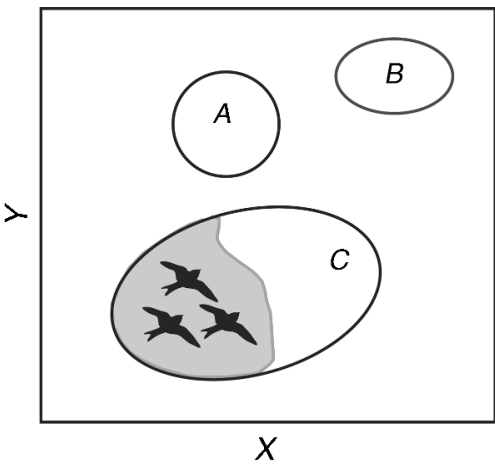

Climate change impacts on biodiversity

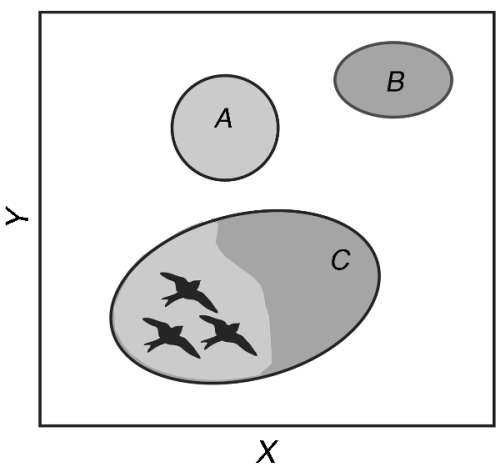

Restoration, translocation, reintroductions

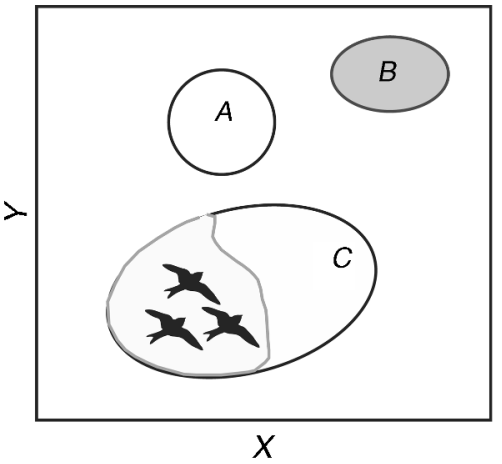

Niche evolution

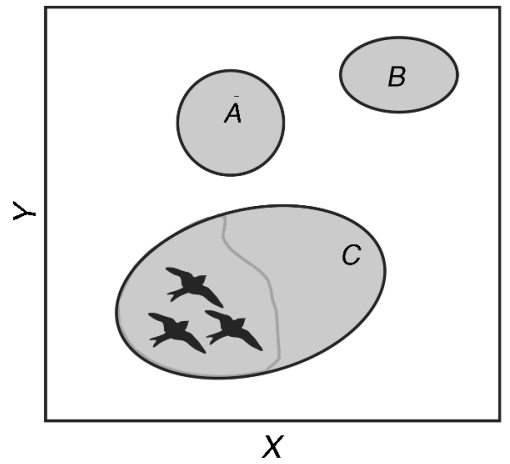

FIG. 3. Examples of uses of bioclimatic models and some of the most common predictions of interest associated with them. Interpretation of the figure should be made in conjunction with Fig. 2. Different shades of grey indicate that alternative predictions are made for the provided examples of use or uses. See Discussion: Cautionary notes... for more details.

potential and abiotically suitable areas rather than on occupied distributional areas of species.

\section{Discovery of new populations or species}

Knowledge about geographic distributions of species is incomplete; here, the prediction of interest includes areas where unknown populations of known species ( $A$ in Fig. 3 ) or populations of unknown species ( $B$ in Fig. 3 ) occur. In either case, this challenge involves using what data are available to identify areas of suitable environmental conditions (Raxworthy et al. 2003). Models may have to be kept quite simple, as occurrence data may be few (de Siqueira et al. 2009). For such uses, errors of commission from the models are not necessarily errors; typically, they are the prediction of interest (i.e., model right, data wrong; see Table 2). Little guidance is available for choosing the right balance between minimization of omission and commission errors in such cases; a practical option is to choose the highest suitability score that achieves a certain minimum omission error (Peterson et al. 2008b) as a threshold. Models need not even be comprehensive in scope (de Siqueira et al. 2009); rather, the aim is to identify a few high-priority sites.

\section{Reserve selection and design}

The prediction of interest in most spatial conservation-planning applications is the occurrence of species in particular areas of conservation interest (the shaded area in the corresponding panel in Fig. 3). Errors of commission are generally unacceptable because they could lead to spending limited resources for conserving species where they do not occur, or where unsuitable conditions exist for the species. For this reason, applications of bioclimatic envelope models in spatial conservation planning are often conservative, and model calibration can focus on minimizing commission errors (e.g., Araújo et al. 2011a). 


\section{Restoration, translocation, or reintroductions}

The common feature of models used to predict areas for restoration, translocation, or reintroductions is that predictions are not about where species are, but where they could be. Notice that the prediction of interest is often areas that are abiotically suitable for the species and free of biotic constraints for its occurrence (area $B$ in Fig. 3). Such models cannot be evaluated with familiar approaches that minimize errors of omission and commission because commission (predicted presences in unoccupied locations) is precisely the prediction of interest. More promising approaches include those that generate predictions mainly focused at reduction of errors of omission (Peterson et al. 2008a) and focus on predictions of presences rather than absences (e.g., Hirzel et al. 2006, Phillips and Elith 2010).

\section{Evaluating risk of species invasions and disease transmission}

Here, the prediction of interest is usually the noninhabited but suitable area that could be invaded ( $B$ in Fig. 3), particularly in the case of invasives where some dispersal barrier is generally what constrains species from achieving full distributional equilibrium. In the case of disease transmission, focus also includes actual distributions. Omission errors will frequently be not erroneous, as areas of overprediction are often what is of interest. Omission error, on the other hand, is almost always important and relevant, and so it is often minimized as much as possible. Of course, other, nonenvironmental factors may modify the suitability or accessibility of a site, so routes of access, presence of competitors, etc., must all be considered in comprehensive studies.

\section{Climate change impacts on biodiversity}

Among the most popular uses of bioclimatic envelope models are inferences about the possible impacts of climate change on the distributions of species. The prediction of interest can be the occupied distributional area of a species, or its potential or abiotically suitable areas for occurrence in the future (Fig. 3). If the prediction concerns occupied distributional areas, estimates of colonization rates as well as climate suitability are required, and approaches that couple bioclimatic envelope models with metapopulation models can be useful (e.g., Keith et al. 2008, Anderson et al. 2009, Fordham et al. 2012). Whether the modeler should weight errors of omission and commission equally in such cases, or down-weight errors of commission, is still a matter of debate.

\section{Niche evolution}

Increasingly, evolutionary ecologists are using bioclimatic envelope models to ask questions regarding the rates of change of niche traits across phylogenies (Wiens and Graham 2005, Peterson 2011). The prediction of interest generally includes the set of environmental combinations that constitute the fundamental ecological niche of the species (Peterson et al. 2011). Such characterizations of fundamental niches are perilous, owing to perpetual complications with limited representation of the full dimensions of these niches on real-life landscapes (Peterson et al. 2011), and tests of niche conservatism are unidirectional in nature: evidence for niche similarity in time and space provides conditional support for the conservatism hypothesis, but if niches appear dissimilar, no firm conclusions can be drawn.

\section{Conclusions}

Ample evidence and precedent support the idea that bioclimatic envelope models can reconstruct environmental correlates of species' geographic distributions. Furthermore, the broad diversity of applications of these models indicates that they represent a potentially powerful tool in understanding whole-range geography and ecology of species. The critical question is under what specific circumstances are such models useful or not? We argue that a clear conceptual framework can place complex ideas in useful contexts and avoid worlds of confusion. In the case of bioclimatic envelope models, the criticisms that have been levelled at the approach fall into this trap: for lack of a detailed and appropriate conceptual context, the criticisms offered are not generally or broadly applicable. That is, the bioclimatic envelope modeling approach is not always guilty of the crimes of which it is accused, but rather it has frequently been guilty of not having placed results in an appropriate or sufficiently clear conceptual framework. We suggest that each application of bioclimatic envelope modeling be subjected to a careful thought process regarding key assumptions before the modeling program is run. The researcher must consider carefully which portions of the distributional area are being sampled, and how completely the environmental range of the study area is being characterized. What is more, the effects of biotic environments and species' mobility must be weighed in choosing that study area in the first place, and assumptions made explicitly regarding why those choices were made. Finally, the desired end product must be weighed against what the modeling exercise is actually designed to estimate. Only with such careful pondering can bioclimatic envelope modeling achieve its full potential.

\section{ACKNOWLEDGMENTS}

M. B. Araújo is funded through the FCT Range Shift project and acknowledges the Spanish Research Council (CSIC), the "Rui Nabeiro/Delta" Biodiversity Chair, and the Danish NSF for support. A. T. Peterson thanks Microsoft Research for support for this work. We thank Jorge Soberón, Richard Pearson, Rob Anderson, Miguel Nakamura, and Enrique Martínez Meyer for stimulating discussion while preparing the book Ecological Niches and Geographical Distributions (Peterson et al. 2011); M. B. Araújo also thanks for discussion the participants of the third Riederalp Workshop "The Utility of Species Distribution Models as Tools for Assessing Impacts of Global Change" (2008). The ideas in this review were matured over the past decade following discussions with several colleagues, and we thank them for that. Raquel Garcia, Gary 
Graves, David Nogués-Bravo, and David Warton provided insightful comments on a previous version of the manuscript; we also thank Mick Ashcroft and two anonymous reviewers for their critical assessments of the manuscript.

\section{Literature Cited}

Akçakaya, H. R., S. H. M. Butchart, G. M. Mace, S. N. Stuart, and C. Hilton-Taylor. 2006. Use and misuse of the IUCN Red List Criteria in projecting climate change impacts on biodiversity. Global Change Biology 12:2037-2043.

Anderson, B. J., H. R. Akçakaya, M. B. Araújo, D. A. Fordham, E. Martinez-Meyer, W. Thuiller, and B. W. Brook. 2009. Dynamics of range margins for metapopulations under climate change. Proceedings of the Royal Society of London B 276:1415-1420.

Anderson, R. P., D. Lew, and A. T. Peterson. 2003. Evaluating predictive models of species' distributions: Criteria for selecting optimal models. Ecological Modelling 162:211-232.

Araújo, M. B., D. Alagador, M. Cabeza, D. Nogués-Bravo, and W. Thuiller. 2011a. Climate change threatens European conservation areas. Ecology Letters 14:484-492.

Araújo, M. B., and A. Guisan. 2006. Five (or so) challenges for species distribution modelling. Journal of Biogeography 33:1677-1688.

Araújo, M. B., and M. Luoto. 2007. The importance of biotic interactions for modelling species distributions under climate change. Global Ecology and Biogeography 16:743-753.

Araújo, M. B., and M. New. 2007. Ensemble forecasting of species distributions. Trends in Ecology and Evolution 22:42-47.

Araújo, M. B., and R. G. Pearson. 2005. Equilibrium of species' distributions with climate. Ecography 28:693-695.

Araújo, M. B., R. G. Pearson, W. Thuiller, and M. Erhard. 2005a. Validation of species-climate impact models under climate change. Global Change Biology 11:1504-1513.

Araújo, M. B., and C. Rahbek. 2006. How does climate change affect biodiversity? Science 313:1396-1397.

Araújo, M. B., A. Rozenfeld, C. Rahbek, and P. A. Marquet. $2011 b$. Using species co-occurrence networks to assess the impacts of climate change. Ecography 34:897-908.

Araújo, M. B., W. Thuiller, and R. G. Pearson. 2006. Climate warming and the decline of amphibians and reptiles in Europe. Journal of Biogeography 33:1712-1728.

Araújo, M. B., W. Thuiller, and N. Yoccoz. 2009. Re-opening the climate envelope reveals macroscale associations with climate in European birds. Proceedings of the National Academy of Sciences USA 106:E45-E46.

Araújo, M. B., R. J. Whittaker, R. Ladle, and M. Erhard. $2005 \mathrm{~b}$. Reducing uncertainty in projections of extinction risk from climate change. Global Ecology and Biogeography 14:529-538.

Araújo, M. B., P. H. Williams, and R. J. Fuller. 2002. Dynamics of extinction and the selection of nature reserves. Proceedings of the Royal Society of London B 269:19711980.

Ashcroft, M. B., K. O. French, and L. A. Chisholm. 2011. An evaluation of environmental factors affecting species distributions. Ecological Modelling 222:524-531.

Aspinall, R. J., J. A. Miller, and J. Franklin. 2009. Calculations on the back of a climate envelope: addressing the geography of species distributions. Proceedings of the National Academy of Sciences USA 106:E44-E44.

Austin, M. 2007. Species distribution models and ecological theory: a critical assessment and some possible new approaches. Ecological Modelling 200:1-19.

Austin, M. P., T. M. Smith, K. P. Van Niel, and A. B. Wellington. 2009. Physiological responses and statistical models of the environmental niche: a comparative study of two co-occurring Eucalyptus species. Journal of Ecology 97:496-507.
Austin, M. P., and K. P. Van Niel. 2011. Improving species distribution models for climate change studies: variable selection and scale. Journal of Biogeography 38:1-8.

Bahn, V., and B. J. McGill. 2007. Can niche-based distribution models outperform spatial interpolation? Global Ecology and Biogeography 16:733-742.

Barve, N., V. Barve, A. Jiménez-Valverde, A. Lira-Noriega, S. P. Maher, A. T. Peterson, J. Soberón, and F. Villalobos. 2011. The crucial role of the accessible area in ecological niche modeling and species distribution modeling. Ecological Modelling 222:1810-1819.

Baselga, A., and M. B. Araújo. 2009. Individualistic vs. community modelling of species distributions under climate change. Ecography 32:55-65.

Beale, C. M., J. J. Lennon, and A. Gimona. 2008. Opening the climate envelope reveals no macroscale associations with climate in European birds. Proceedings of the National Academy of Sciences USA 105:14908-14912.

Botkin, D., et al. 2007. Forecasting effects of global warming on biodiversity. BioScience 57:227-236.

Bourg, N. A., W. J. McShea, and D. E. Gill. 2005. Putting a CART before the search: successful habitat prediction for a rare forest herb. Ecology 86:2793-2804.

Breiman, L. 2001. Random forest. Machine Learning 45:5-32.

Broennimann, O., and A. Guisan. 2008. Predicting current and future biological invasions: both native and invaded ranges matter. Biology Letters 4:585-589.

Broennimann, O., U. A. Treier, H. Müller-Schärer, W. Thuiller, A. T. Peterson, and A. Guisan. 2007. Evidence of climatic niche shift during biological invasion. Ecology Letters 10:701-709.

Brook, B. W., H. R. Akçakaya, D. A. Keith, G. M. Mace, R. G. Pearson, and M. B. Araújo. 2009. Integrating bioclimate with population models to improve forecasts of species extinctions under climate change. Biology Letters 5:723-725.

Buckley, L., S. Waaser, H. MacLean, and R. Fox. 2011. Does including physiology improve species distribution model predictions of responses to recent climate change? Ecology 92:2214-2221.

Carnaval, A. C., and C. Moritz. 2008. Historical climate modelling predicts patterns of current biodiversity in the Brazilian Atlantic forest. Journal of Biogeography 35:11871201.

Chapman, D. S. 2010. Weak climatic associations among British plant distributions. Global Ecology and Biogeography 19:831-841.

Chevin, L.-M., R. Lande, and G. M. Mace. 2010. Adaptation, plasticity, and extinction in a changing environment: towards a predictive theory. PLoS Biology 8:e1000357.

Clark, J. S., et al. 1998. Reid's paradox of rapid plant migration. BioScience 48:13-24.

Collingham, Y. C., and B. Huntley. 2000. Impacts of habitat fragmentation and patch size upon migration rates. Ecological Applications 10:131-144.

Colwell, R. K., G. Brehm, C. L. Cardelús, A. C. Gilman, and J. T. Longino. 2008. Global warming, elevational range shifts, and lowland biotic attrition in the wet tropics. Science 322:258-261.

de Siqueira, M. F., G. Durigan, P. de Marco Júnior, and A. T. Peterson. 2009. Something from nothing: using landscape similarity and ecological niche modeling to find rare plant species. Journal for Nature Conservation 17:25-32.

Diniz-Filho, J. A., L. M. Bini, T. F. L. B. Rangel, R. D. Loyola, C. Hof, D. Nogués-Bravo, and M. B. Araújo. 2009. Partitioning and mapping uncertainties in ensembles of forecasts of species turnover under climate changes. Ecography $32: 1-10$.

Dobrowski, S. Z., J. H. Thorne, J. Greenberg, H. D. Saffort, A. R. Mynsberge, S. M. Crimmins, and A. K. Swanson. 2011. Modeling plant distributions over 75 years of measured 
climate change in California, USA: relating transferability to species traits. Ecological Monographs 81:241-257.

Dormann, C. F. 2007. Promising the future? Global change projections of species distributions. Basic and Applied Ecology 8:387-397.

Duncan, R. P., P. Cassey, and T. M. Blackburn. 2009. Do climate envelope models transfer? A manipulative test using dung beetle introductions. Proceedings of the Royal Society of London B 276:1449-1457.

Dunn, R. R., N. C. Harris, R. K. Colwell, L. P. Koh, and N. S. Sodhi. 2009. The sixth mass coextinction: are most endangered species parasites and mutualists? Proceedings of the Royal Society B: Biological Sciences 276:3037-3045.

Elith, J., S. Ferrier, F. Huettmann, and J. Leathwick. 2005. The evaluation strip: a new and robust method for plotting predicted responses from species distribution models. Ecological Modelling 186:280-289.

Elith, J., and C. H. Graham. 2009. Do they? How do they? WHY do they differ? On finding reasons for differing performances of species distribution models. Ecography 32:66-77.

Elith, J., M. Kearney, and S. Phillips. 2010. The art of modelling range-shifting species. Methods in Ecology and Evolution 1:330-342.

Elith, J., and J. R. Leathwick. 2009. Species distribution models: ecological explanation versus prediction across space and time. Annual Review of Ecology, Evolution, and Systematics 40:677-697.

Elith, J., J. R. Leathwick, and T. Hastie. 2008. A working guide to boosted regression trees. Journal of Animal Ecology 77:802-813.

Engler, R., and A. Guisan. 2009. MigClim: predicting plant distribution and dispersal in a changing climate. Diversity and Distributions 15:590-601.

Feria, T. P., and A. T. Peterson. 2002. Using point occurrence data and inferential algorithms to predict local communities of birds. Diversity and Distributions 8:49-56.

Fitzpatrick, M., and W. Hargrove. 2009. The projection of species distribution models and the problem of non-analog climate. Biodiversity and Conservation 18:2255-2261.

Fitzpatrick, M. C., J. F. Weltzin, N. J. Sanders, and R. R. Dunn. 2007. The biogeography of prediction error: Why does the introduced range of the fire ant over-predict its native range? Global Ecology and Biogeography 16:24-33.

Fordham, D. A., et al. 2012. Plant extinction risk under climate change: are forecast range shifts alone a good indicator of species vulnerability to global warming. Global Change Biology 18:1357-1371.

Franklin, J. 2009. Mapping species distributions: spatial inference and prediction. Cambridge University Press, Cambridge, UK.

Freeman, E. A., and G. G. Moisen. 2008. A comparison of the performance of threshold criteria for binary classification in terms of predicted prevalence and kappa. Ecological Modelling 217:48-58.

Gallien, L., T. Münkemüller, C. H. Albert, I. Boulangeat, and W. Thuiller. 2010. Predicting potential distributions of invasive species: where to go from here? Diversity and Distributions 16:331-342.

Garcia, R. A., N. D. Burgess, M. Cabeza, C. Rahbek, and M. B. Araújo. 2012. Exploring consensus in 21st century projections of climatically suitable areas for African vertebrates. Global Change Biology 18:1253-1269.

Gaston, K. 2003. The structure and dynamics of geographic ranges. Oxford University Press, Oxford, UK.

Gonzalez, P., R. P. Neilson, J. M. Lenihan, and R. J. Drapek. 2010. Global patterns in the vulnerability of ecosystems to vegetation shifts due to climate change. Global Ecology and Biogeography 19:755-768.

Green, R. E., Y. C. Collingham, S. G. Willis, R. D. Gregory, K. W. Smith, and B. Huntley. 2008. Performance of climate envelope models in retrodicting recent changes in bird population size from observed climatic change. Biology Letters 4:599-602.

Guisan, A., and W. Thuiller. 2005. Predicting species distribution: offering more than simple habitat models. Ecology Letters 8:993-1009.

Hampe, A. 2004. Bioclimate envelope models: what they detect and what they hide. Global Ecology and Biogeography 13:469-471.

Hampe, A., and A. S. Jump. 2011. Climate relicts: past, present, future. Annual Review of Ecology, Evolution, and Systematics 42:313-333.

Heidy Kikillus, K., K. M. Hare, and S. Hartley. 2010. Minimizing false-negatives when predicting the potential distribution of an invasive species: a bioclimatic envelope for the red-eared slider at global and regional scales. Animal Conservation 13:5-15.

Heikkinen, R. K., M. Luoto, M. B. Araújo, R. Virkkala, W. Thuiller, and M. T. Sykes. 2006. Methods and uncertainties in bioclimatic modelling under climate change. Progress in Physical Geography 30:751-777.

Hickling, R., D. B. Roy, J. K. Hill, R. Fox, and C. D. Thomas. 2006. The distributions of a wide range of taxonomic groups are expanding polewards. Global Change Biology 12:450455.

Hill, J. K., C. D. Thomas, and B. Huntley. 1999. Climate and habitat availability determine 20 th century changes in a butterfly's range margin. Proceedings of the Royal Society of London B 266:1197-1206.

Hirzel, A. H., and G. L. Lay. 2008. Habitat suitability modelling and niche theory. Journal of Applied Ecology 45:1372-1381.

Hirzel, A. H., G. Le Lay, V. Helfer, C. Randin, and A. Guisan. 2006. Evaluating the ability of habitat suitability models to predict species presences. Ecological Modelling 199:142-152.

Hodges, J. S. 1991. Six (or so) things you can do with a bad model. Operations Research 39:355-365.

Hof, C., C. Rahbek, and M. B. Araújo. 2010. Phylogenetic signals in the climatic niches of the world's amphibians. Ecography 33:242-250.

Huntley, B., P. Barnard, R. Altwegg, L. Chambers, B. W. T. Coetzee, L. Gibson, P. A. R. Hockey, D. G. Hole, G. F. Midgley, L. G. Underhill, and S. G. Willis. 2010. Beyond bioclimatic envelopes: dynamic species' range and abundance modelling in the context of climatic change. Ecography 33:621-626.

Huntley, B., Y. C. Collingham, S. G. Willis, and R. E. Green. 2008. Potential impacts of climatic change on European breeding birds. PLOS ONE 3:e1439.

Jiménez-Valverde, A., N. Barve, A. Lira-Noriega, S. P. Maher, Y. Nakazawa, M. Papeş, J. Soberón, J. Sukumaran, and A. T. Peterson. 2011a. Dominant climate influences on North American bird distributions. Global Ecology and Biogeography 20:114-118.

Jiménez-Valverde, A., J. M. Lobo, and J. Hortal. 2008. Not as good as they seem: the importance of concepts in species distribution modelling. Diversity and Distributions 14:885890.

Jiménez-Valverde, A., A. T. Peterson, J. Soberón, J. Overton, P. Aragón, and J. M. Lobo. 2011b. Use of niche models in invasive species risk assessments. Biological Invasions 13:2785-2797.

Kearney, M. R. 2006. Habitat, environment and niche: What are we modelling? Oikos 115:186-191.

Kearney, M., and W. P. Porter. 2004. Mapping the fundamental niche: Physiology, climate, and the distribution of a nocturnal lizard. Ecology 85:3119-3131.

Kearney, M. R., B. A. Wintle, and W. P. Porter. 2010. Correlative and mechanistic models of species distribution provide congruent forecasts under climate change. Conservation Letters 3:203-213. 
Keith, D. A., H. R. Akçakaya, W. Thuiller, G. F. Midgley, R. G. Pearson, S. J. Phillips, H. M. Regan, M. B. Araújo, and T. G. Rebelo. 2008. Predicting extinction risks under climate change: coupling stochastic population models with dynamic bioclimatic habitat models. Biology Letters 4:560563.

Kharouba, H. M., A. C. Algar, and J. T. Kerr. 2009. Historically calibrated predictions of butterfly species' range shift using global change as a pseudo-experiment. Ecology 90:2213-2222

Kozak, K. H., and J. J. Wiens. 2006. Does niche conservatism promote speciation? A case study in North American salamanders. Evolution 60:2604-2621.

Kujala, H., M. B. Araújo, W. Thuiller, and M. Cabeza. 2011. Misleading results from conventional gap analysis: messages from the warming north. Biological Conservation 144:2450 2458

Ladle, R., P. Jepson, M. B. Araújo, and R. J. Whittaker. 2004. Dangers of crying wolf over risks of extinction. Nature 428:799.

Latimer, A. M., S. Wu, A. E. Gelfand, and J. A. Silander. 2006. Building statistical models to analyze species distributions. Ecological Applications 16:33-50.

Lawler, J. J., S. L. Shafer, D. White, P. Kareiva, E. P. Maurer, A. R. Blaustein, and P. J. Bartlein. 2009. Projected climateinduced faunal change in the Western Hemisphere. Ecology 90:588-597.

Lenoir, J., J. C. Gégout, P. A. Marquet. P. de Ruffray, and H. Brisse. 2008. A significant upward shift in plant species optimum elevation during the 20th century. Science 320:1768-1771.

Liu, C., P. M. Berry, T. P. Dawson, and R. G. Pearson. 2005. Selecting thresholds of occurrence in the prediction of species distributions. Ecography 28:385-393.

Losos, J. B. 2008. Phylogenetic niche conservatism, phylogenetic signal and the relationship between phylogenetic relatedness and ecological similarity among species. Ecology Letters 11:995-1003.

Marmion, M., M. Parviainen, M. Luoto, R. K. Heikkinen, and W. Thuiller. 2009. Evaluation of consensus methods in predictive species distribution modelling. Diversity and Distributions 15:59-69.

Martínez-Meyer, E., and A. T. Peterson. 2006. Conservatism of ecological niche characteristics in North American plant species over the Pleistocene-to-Recent transition. Journal of Biogeography 33:1779-1789.

Medley, K. A. 2010. Niche shifts during the global invasion of the Asian tiger mosquito, Aedes albopictus Skuse (Culicidae), revealed by reciprocal distribution models. Global Ecology and Biogeography 19:122-133.

Meier, E. S., F. Kienast, P. B. Pearman, J.-C. Svenning, W. Thuiller, M. B. Araújo, A. Guisan, and N. E. Zimmermann. 2010. Biotic and abiotic variables show little redundancy in explaining tree species distributions. Ecography 33:1038-1048.

Miller, J. 2010. Species distribution modeling. Geography Compass 4:490-509.

Mohler, C. L. 1983. Effect of sampling pattern on estimation of species distributions along gradients. Vegetatio 54:97-102.

Monahan, W. B. 2009. A mechanistic niche model for measuring species' distributional responses to seasonal temperature gradients. PLoS ONE 4:e7921.

Nenzén, H. K., and M. B. Araújo. 2011. Choice of threshold alters projections of species range shifts under climate change. Ecological Modelling 222:3346-3354.

Nogués-Bravo, D. 2009. Predicting the past distribution of species climatic niches. Global Ecology and Biogeography 18:521-531

Nogués-Bravo, D., J. Rodriguez, J. Hortal, P. Batra, and M. B. Araújo. 2008. Climate change, humans, and the extinction of the woolly mammoth. PLoS Biology 6:e79.
Oreskes, N., K. S. Shrader-Frechette, and K. Belitz. 1994. Verification, validation, and confirmation of numerical models in the earth sciences. Science 263:641-646.

Parmesan, C., and G. Yohe. 2003. A globally coherent fingerprint of climate change impacts across natural systems. Nature 421:37-42.

Pearce, J., and S. Ferrier. 2001. The practical value of modelling relative abundance of species for regional conservation planning: a case study. Biological Conservation 98:33-43.

Pearman, P. B., A. Guisan, O. Broennimann, and C. F. Randin. 2008. Niche dynamics in space and time. Trends in Ecology and Evolution 23:149-158.

Pearson, R. G. 2007. Species' distribution modeling for conservation educators and practitioners. Center for Biodiversity and Conservation, American Museum of Natural History, New York, New York, USA. http://ncep.amnh.org

Pearson, R. G., T. E. Dawson, and C. Liu. 2004. Modelling species distributions in Britain: a hierarchical integration of climate and land-cover data. Ecography 27:285-298.

Pereira, H. M., et al. 2010. Scenarios for global biodiversity in the 21st century. Science 330:1496-1501.

Peterson, A. T. 2003. Predicting the greography of species' invasions via ecological niche modeling. Quaterly Review of Biology 78:419-433.

Peterson, A. T. 2011. Ecological niche conservatism: a timestructured review of evidence. Journal of Biogeography 38:817-827.

Peterson, A. T., B. W. Benz, and M. Papeş. 2007. Highly pathogenic $\mathrm{H} 5 \mathrm{~N} 1$ avian influenza: entry pathways into North America via bird migration. PLoS ONE 2:e261.

Peterson, A. T., R. R. Lash, D. S. Carrol, and K. M. Johnson. 2006. Geographic potential for outbreaks of Marburg hemorrhagic fever. American Journal of Tropical Medicine and Hygiene 75:9-15.

Peterson, A. T., M. Papeş, and J. Soberón. 2008a. Rethinking receiver operating characteristic analysis applications in ecological niche modeling. Ecological Modelling 213:63-72.

Peterson, A. T., J. Soberón, R. G. Pearson, R. P. Anderson, M. Nakamura, E. Martinez-Meyer, and M. B. Araújo. 2011. Ecological niches and geographical distributions. Princeton University Press, Princeton, New Jersey, USA.

Peterson, A. T., J. Soberón, and V. Sánchez-Cordero. 1999. Conservatism of ecological niches in evolutionary time. Science 285:1265-1267.

Peterson, A. T., A. Stewart, K. I. Mohamed, and M. B. Araújo. $2008 \mathrm{~b}$. Shifting global invasive potential of European plants with climate change. PLoS ONE 3:e2441.

Phillips, S. J., and M. Dudík. 2008. Modeling of species distributions with Maxent: new extensions and a comprehensive evaluation. Ecography 31:161-175.

Phillips, S. J., M. Dudík, J. Elith, C. H. Graham, A. Lehmann, J. Leathwick, and S. Ferrier. 2009. Sample selection bias and presence-only distribution models: implications for background and pseudo-absence data. Ecological Applications 19:181-197.

Phillips, S. J., and J. Elith. 2010. POC plots: calibrating species distribution models with presence-only data. Ecology 91:2476-2484.

Raes, N., and H. ter Steege. 2007. A null-model for significance testing of presence-only species distribution models. Ecography 30:727-736.

Randin, C. F., R. Engler, S. Normand, M. Zappa, N. E. Zimmermann, P. B. Pearman, P. Vittoz, W. Thuiller, and A. Guisan. 2009. Climate change and plant distribution: local models predict high-elevation persistence. Global Change Biology 15:1557-1569.

Raxworthy, C. J., E. Martínez-Meyer, N. Horning, R. A. Nussbaum, G. E. Schneider, M. A. Ortega-Huerta, and A. T. Peterson. 2003. Predicting distributions of known and unknown reptile species in Madagascar. Nature 426:837-841. 
Rodríguez-Sánchez, F., and J. Arroyo. 2008. Reconstructing the demise of Tethyan plants: climate-driven range dynamics of Laurus since the Pliocene. Global Ecology and Biogeography 17:685-695.

Root, T. 1988. Energy constraints on avian distributions and abundances. Ecology 69:330-339.

Root, T. L., J. T. Price, K. R. Hall, S. H. Schneider, C. Rosenzweig, and J. A. Pounds. 2003. Fingerprints of global warming on wild animals and plants. Nature 421:57-60.

Scott, J. M., P. J. Heglund, J. B. Haufler, M. Morrison, M. G. Raphael, W. B. Wall, and F. Samson, editors. 2002. Predicting species occurrences: issues of accuracy and scale. Island Press, Covelo, California, USA.

Sinclair, S. J., M. D. White, and G. R. Newell. 2010. How useful are species distribution models for managing biodiversity under future climates? Ecology and Society 15(1):8. http://www.ecologyandsociety.org/vol15/iss1/art8

Soberón, J. 2007. Grinnellian and Eltonian niches and geographic distributions of species. Ecology Letters 10:1115-1123.

Soberón, J. M. 2010. Niche and area of distribution modeling: a population ecology perspective. Ecography 33:159-167.

Soberón, J., and M. Nakamura. 2009. Niches and distributional areas: concepts, methods, and assumptions. Proceedings of the National Academy of Sciences USA 106:19644-19650.

Soberón, J., and A. T. Peterson. 2011. Ecological niche shifts and environmental space anisotropy: A cautionary note. Revista Mexicana de Biodiversidad 82:1348-1353.

Svenning, J.-C., and F. Skov. 2004. Limited filling of the potential range in European tree species. Ecology Letters 7:565-573.

Thomas, C. D. 2010. Climate, climate change and range boundaries. Diversity and Distributions 16:488-495.

Thomas, C. D., et al. 2004. Extinction risk from climate change. Nature 427:145-148.

Thuiller, W. 2007. Biodiversity: climate change and the ecologist. Nature 448:550-552.

Thuiller, W., C. Albert, M. B. Araújo, P. M. Berry, M. Cabeza, A. Guisan, T. Hickler, G. F. Midgley, J. Paterson, F. M. Schurr, M. T. Sykes, and N. E. Zimmermann. 2008. Predicting global change impacts on plant species' distributions: future challenges. Perspectives in Plant Ecology, Evolution and Systematics 9:137-152.

Thuiller, W., M. B. Araújo, R. G. Pearson, R. J. Whittaker, L. Brotons, and S. Lavorel. 2004a. Biodiversity conservation: uncertainty in predictions of extinction risk. Nature 430 . doi:10.1038/nature02716

Thuiller, W., L. Brotons, M. B. Araújo, and S. Lavorel. $2004 b$. Effects of restricting environmental range of data to project current and future species distributions. Ecography 27:165172.

Thuiller, W., S. Lavergne, C. Roquet, I. Boulangeat, and M. B. Araújo. 2011. Consequences of climate change on the tree of life in Europe. Nature 470:531-534.

Thuiller, W., S. Lavorel, M. B. Araújo, M. T. Sykes, and I. C. Prentice. 2005. Climate change threats to plant diversity in Europe. Proceedings of the National Academy of Sciences USA 102:8245-8250.

Tingley, M. W., W. B. Monahan, S. R. Beissinger, and C. Moritz. 2009. Birds track their Grinnellian niche through a century of climate change. Proceedings of the National Academy of Sciences USA 106:19637-19643.

Triviño, M., W. Thuiller, M. Cabeza, T. Hickler, and M. B. Araújo. 2011. The contribution of vegetation and landscape configuration for predicting environmental change impacts on Iberian birds. PLoS ONE 6:e29373.

VanDerWal, J., L. P. Shoo, C. Graham, and S. E. Williams. 2009a. Selecting pseudo-absence data for presence-only distribution modeling: How far should you stray from what you know? Ecological Modelling 220:589-594.
VanDerWal, J., L. P. Shoo, C. N. Johnson, and S. E. Williams. 2009b. Abundance and the environmental niche: environmental suitability estimated from niche models predicts the upper limit of local abundance. American Naturalist 174:282-291.

Vega, R., C. Fløjgaard, A. Lira-Noriega, Y. Nakazawa, J.-C. Svenning, and J. B. Searle. 2010. Northern glacial refugia for the pygmy shrew Sorex minutus in Europe revealed by phylogeographic analyses and species distribution modelling. Ecography 33:260-271.

Villemant, C., M. Barbet-Massin, A. Perrard, F. Muller, O. Gargominy, F. Jiguet, and Q. Rome. 2011. Predicting the invasion risk by the alien bee-hawking Yellow-legged hornet Vespa velutina nigrithorax across Europe and other continents with niche models. Biological Conservation 144:21422150 .

Von Humboldt, A., and A. Bonpland. 1805. Essai sur la géographie des plantes; acompagné d'un tableau physique des régions êquinoxales. Paris. [Republished 1971, Theatrum Orbis Terrarum, Amsterdam, The Netherlands.]

Waltari, E., R. J. Hijmans, A. T. Peterson, A. S. Nyari, S. L. Perkins, and R. P. Guralnick. 2007. Locating Pleistocene refugia: comparing phylogeographic and ecological niche model predictions. PLOS ONE 2:e563.

Walther, G.-R., S. Berger, and M. T. Sykes. 2005. An ecological 'footprint' of climate change. Proceedings of the Royal Society London Series B 272:1427-1432.

Warren, D. L., R. E. Glor, and M. Turelli. 2008. Environmental niche equivalency versus conservatism: Quantitative approaches to niche evolution. Evolution 62:2868-2883.

Whittaker, R. H. 1975. Communities and ecosystems. Second edition. Macmillan, New York, New York, USA.

Wiens, J. J., and M. J. Donoghue. 2004. Historical biogeography, ecology, and species richness. Trends in Ecology and Evolution 19:639-644.

Wiens, J. J., and C. H. Graham. 2005. Niche conservatism: Integrating evolution, ecology, and conservation biology. Annual Review of Ecology, Evolution, and Systematics 36:519-539.

Williams, J. W., B. N. Shuman, and T. Webb. 2001. Dissimilarity analysis of late-quaternary vegetation and climate in Eastern North America. Ecology 82:3346-3362.

Williams, P. H., L. Hannah, S. Andelman, G. F. Midgley, M. B. Araújo, G. Hughes, L. L. Manne, E. Martinez-Meyer, and R. G. Pearson. 2005. Planning for climate change: identifying minimum-dispersal corridors for the Cape Proteaceae. Conservation Biology 19:1063-1074.

Wilson, K. A., M. I. Westphal, H. P. Possingham, and J. Elith. 2005a. Sensitivity of conservation planning to different approaches to using predicted species distribution data. Biological Conservation 122:99-112.

Wilson, R. J., D. Gutiérrez, D. Martínez, R. Agudo, and V. J. Monserrat. 2005b. Changes to the elevational limits and extent of species ranges associated with climate change. Ecology Letters 8:1138-1146.

Wisz, M. S., and A. Guisan. 2009. Do pseudo-absence selection strategies influence species distribution models and their predictions? An information-theoretic approach based on simulated data. BMC Ecology 9:8. doi: 10.1186/ 1472-6785-9-8

Woodward, F. I., and B. G. Williams. 1987. Climate and plant distribution at global and local scales. Plant Ecology 69:189 197.

Wright, J. W., K. F. Davies, J. A. Lau, A. C. McCall, and J. K. McKay. 2006. Experimental verification of ecological niche modeling in a heterogeneous environment. Ecology 87:24332439.

Zurell, D., F. Jeltsch, C. F. Dormann, and B. Schröder. 2009. Static species distribution models in dynamically changing systems: how good can predictions really be? Ecography 32:733-744. 